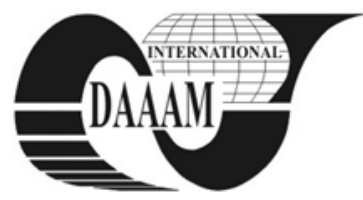

Annals of DAAAM for 2011 \& Proceedings of the 22nd International DAAAM Symposium, Volume 22, No. 1, ISSN 1726-9679 ISBN 978-3-901509-83-4, Editor B. Katalinic, Published by DAAAM International, Vienna, Austria, EU, 2011 Make Harmony between Technology and Nature, and Your Mind will Fly Free as a Bird Annals \& Proceedings of DAAAM International 2011

\title{
COMBINED EFFECT OF DEFORMATION AND HEAT TREATMENT ON CARBIDE DISTRIBUTION IN RST37-2 STEEL
}

\author{
KUCEROVA, L[udmila]; JIRKOVA, H[ana]; JANDOVA, D[agmar] \& MASEK, B[ohuslav]
}

\begin{abstract}
The formability of cold formed steel is conventionally improved by soft annealing which ensure spheroidization of carbides in final microstructure. Soft annealing is however a long and energy consuming process and therefore this article deals with the attempt to replace it by thermo-mechanical processing which combined hot deformation applied around $A_{1}$ temperature with controlled heat treatment. Several strategies either with two deformation steps or with intensive incremental deformation were proposed with deformation temperatures of $700^{\circ} \mathrm{C}$ and $740^{\circ} \mathrm{C}$ and various subsequent holds at deformation temperature. The best results were obtained by the strategy with two deformation steps at $740^{\circ} \mathrm{C}$ (total $\varphi=2.1$ ) followed by 300 s hold, which resulted in carbide spheroidization.
\end{abstract}

Key words: carbide morphology, spheroidization, thermomechanical treatment

\section{INTRODUCTION}

There have been many application possibilities for cold formed steels with pearlite microstructure. The conventional after-treatment consists of a long time soft annealing to ensure spheroidization of pearlite and thus also better ductility. Approximately 160000 tons per year of medium-carbon steel are spheroidized for fastener applications alone (O'Brien, 1997). As this process is rather cost intensive, any reduction of the temperature or time of spheroidization could result in a major energy savings (Karadeniz, 2008; Chen-Chia, 1985).

Recently investigated spheroidization processes can be divided into four groups: isothermal annealing at a temperature slightly below $A_{1}$, thermal cycling near $A_{1}$, isothermal annealing with the aid of prior cold work and finally, hot deformation before, during or after the transformation of austenite to pearlite (Kamyabi-Gol, 2010).

This article deals with the last of the above mentioned groups, describing processing strategies incorporating different amount and distribution of hot deformation applied around $\mathrm{A}_{1}$ temperature. The aim of the research is to propose processing strategy that could be successfully applied in real technological processes, which can produce the semi-products with desired shape and microstructure in the same step.

\section{EXPERIMENTAL PROGRAM}

Experimental program was carried out at RSt37-2 (S232 JRC) steel. It was an unalloyed structural steel (Tab. 1) after cold drawing with ferritic-pearlitic microstructure, the pearlite having lamellar morphology. In this state the steel possessed ultimate strength $546 \mathrm{MPa}$, yield strength $477 \mathrm{MPa}$, ductility $21 \%$ and hardness $201 \mathrm{HV} 10$. After conventional soft annealing the hardness dropped to $100 \mathrm{HV} 10$. Low-temperature thermo-mechanical processing of this steel was done using thermo-mechanical simulator, which ensures precise control of thermal and deformation parameters. Several processing strategies were proposed to investigate the influence of the amount of applied deformation and the distribution of deformation steps on carbide morphology.

\begin{tabular}{|c|c|c|c|c|c|c|}
\hline $\mathrm{C}$ & $\mathrm{P}$ & $\mathrm{S}$ & $\mathrm{Mn}$ & $\mathrm{Si}$ & $\mathrm{Cu}$ & $\mathrm{N}$ \\
\hline 0.08 & 0.022 & 0.023 & 0.65 & 0.16 & 0.05 & 0.004 \\
\hline
\end{tabular}

Tab.1. Chemical composition of RSt37-2 (S232 JRC) steel

Dilatometric results suggested that $\mathrm{A}_{\mathrm{r} 1}$ temperature is shifted nearly to $770^{\circ} \mathrm{C}$ for used heating rates around $30^{\circ} \mathrm{C} / \mathrm{s}$. To keep the processing energy-efficient, lower soaking temperatures of $700^{\circ} \mathrm{C}$ and $740^{\circ} \mathrm{C}$ were chosen (Tab. 1). Constant hold of 10s was carried out at these temperatures prior to deformation. Heating temperature and hold were optimized in previous work (Jirkova, 2010). Processing parameters to be considered in this work were deformation distribution and subsequent hold at the deformation temperature. As deformation distribution varies in different real technologies, two main groups of processing strategies were designed to compare the influence of incremental deformation and deformation distributed in two individual steps. The deformation was in all cases applied at the heating temperature, however local sharp increase of temperature occurred during each deformation step. The total logarithmic deformation of strategies with two deformation steps was always equal to 2.1 (Tab. 2). It consisted of tensile deformation with $\varphi=0.33$ and subsequent intensive compression deformation with $\varphi=1.7$. Incremental deformation was applied in 60 deformation steps with $\varphi=6.7$ and it was accompanied with final compression deformation with $\varphi=1.1$. It was furthermore necessary to estimate the effect of diffusion on carbide spheroidization. Reference samples were cooled from $740^{\circ} \mathrm{C}$ and $700^{\circ} \mathrm{C}$ directly after both deformation strategies. Additional holds of 50s, 100s, $300 \mathrm{~s}$ were performed at $740^{\circ} \mathrm{C}$ after the deformation for the strategy with two deformation steps. As the shorter holds had no distinctive effect on carbide morphology, only 300s hold was used for the strategy with incremental deformation (Tab.2).

\begin{tabular}{|c|c|c|c|c|}
\hline $\begin{array}{l}\text { Heating } \\
{\left[{ }^{\circ} \mathrm{C} / \mathrm{s}\right]}\end{array}$ & $\begin{array}{l}\text { Deformation } \\
\text { steps }\end{array}$ & $\varphi[-]$ & $\begin{array}{c}\text { Hold after } \\
\text { def. [s] }\end{array}$ & HV10 \\
\hline \multirow{4}{*}{$740 / 10$} & \multirow{5}{*}{$\begin{array}{c}\text { Tension }+ \\
\text { compression }\end{array}$} & \multirow{5}{*}{$0.3+1.7$} & - & 166 \\
\hline & & & 50 & 135 \\
\hline & & & 100 & 137 \\
\hline & & & 300 & 121 \\
\hline 700/10 & & & - & 181 \\
\hline \multirow{2}{*}{$740 / 10$} & \multirow{3}{*}{$\begin{array}{c}60 \mathrm{x} \\
\text { incremental } \\
\text { deformation }+ \\
\text { compression }\end{array}$} & \multirow{3}{*}{$6.7+1.1$} & - & 170 \\
\hline & & & 300 & 130 \\
\hline $700 / 10$ & & & - & 170 \\
\hline
\end{tabular}

Tab 2. Thermo-mechanical processing parameters 


\section{RESULTS AND DISSCUSION}

Based on the results of previous experiments, both strategies with two deformations and with incremental deformations were first tested with heating temperatures of $740^{\circ} \mathrm{C}$ and without additional hold at this temperature. Refined recrystallized ferrite grains were observed in both microstructures with the size around $1 \mu \mathrm{m}$ (Fig.1, Fig. 2). The processing with two individual deformations steps was more successful in braking pearlitic areas into smaller parts. However in both cases pearlite remained lamellar and the microstructure exhibits distinctive deformation texture and the hardness was in both cases relatively high, around $170 \mathrm{HV} 10$.

Addition of the hold of $300 \mathrm{~s}$ at $740^{\circ} \mathrm{C}$ after deformation turned out to be very beneficial for both strategies. Resulting ferrite grains were coarser than in the previous cases, as the recrystallization had enough time to proceed. This was also reflected by the drop of hardness by approximately $27 \%$, to 121 and 130 HV10. Significant refinement of pearlitic areas was observed for the strategy with incremental deformation and pearlitic areas were also more homogenously distributed along ferrite grain boundaries (Fig. 3). Even better results were obtained for strategy with two deformations steps, where relatively large parts of the sample underwent successful spheroidization of carbides. These carbides were also homogeneously distributed in ferrite matrix (Fig. 4). To further investigate the effect of diffusion on carbide morphology, another two strategies were proposed, with two deformation steps and shorter holds of 50s and 100s. Even after the shorter holds at $740^{\circ} \mathrm{C}$, the pearlite areas were relatively small and evenly distributed along grain boundaries, however no spheroidized carbides were observed.

Processing strategies with lower heating and deformation temperature of $700^{\circ} \mathrm{C}$ and without additional hold resulted in apparently deformed microstructures (Fig. 5). However, the orientation of deformed structures was in both cases lower than for the same strategies with higher heating temperature of $740^{\circ} \mathrm{C}$. Very fine ferrite grains were again found in both microstructures and high hardness values were therefore measured for both strategies, reaching 170 HV10 for strategy with incremental deformation and even 180 HV10 for the strategy with two deformations. As in the case of higher heating temperature it was also realized that strategy with two deformation steps achieved smaller and more evenly distributed pearlite areas

\section{CONLCUSION}

It was found out, that microstructure of RSt37-2 (S235JRC) steel can be significantly refined by deformation applied around $\mathrm{A}_{1}$ temperature. Two individual deformations were more successful in separating pearlite into smaller areas than intensive incremental deformation and they also achieved more even distribution of pearlite.

Diffusion played an important role in spheroidization process and the hold of $300 \mathrm{~s}$ at $740^{\circ} \mathrm{C}$ applied after two step deformation resulted in spheroidization of carbides in central part of the sample. It suggests that this processing can after further optimization replace time and energy consuming soft annealing.

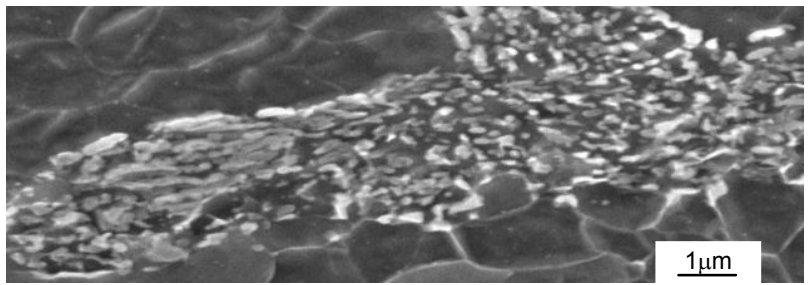

Fig. $1.740^{\circ} \mathrm{C} /$ two deformations

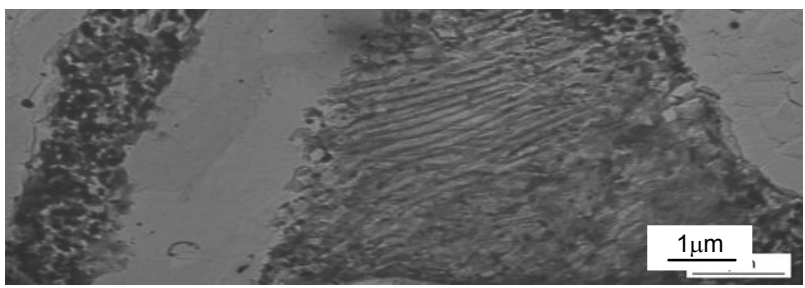

Fig. $2.740^{\circ} \mathrm{C} / 60 \mathrm{x}$ incremental deformations + compression

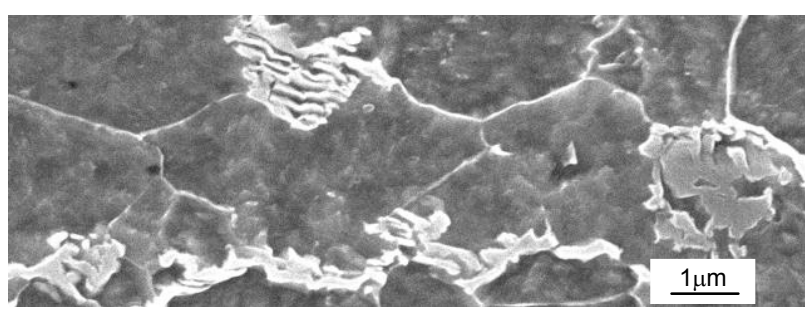

Fig. 3. $740^{\circ} \mathrm{C} / 60 \mathrm{x}$ incremental deformations + compression/ 300s hold

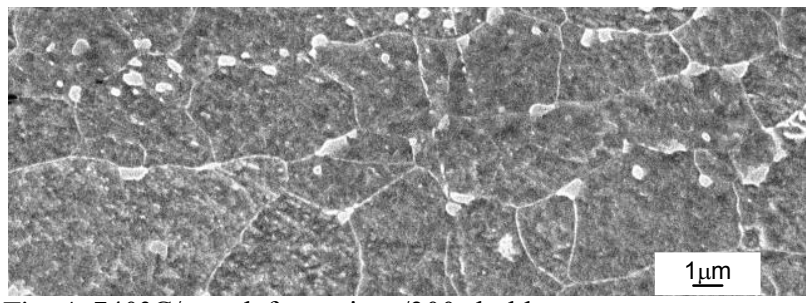

Fig. $4.740^{\circ} \mathrm{C} /$ two deformations $/ 300$ s hold

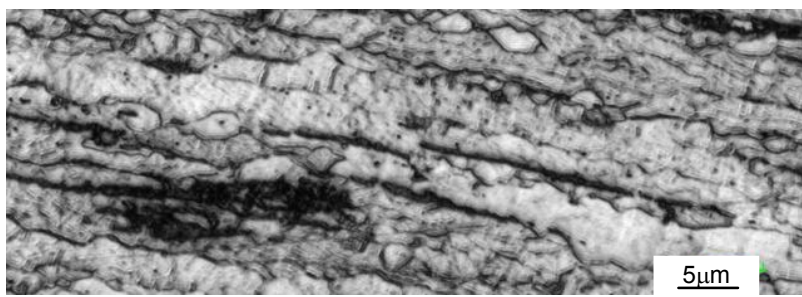

Fig. $5.700^{\circ} \mathrm{C} / 60$ incremental deformations + compression

\section{ACKNOWLEDGEMENTS}

This paper includes results created within the project $1 \mathrm{M} 06032$ Research Centre of Forming Technology and within the project P107/10/2272 Accelerated Carbide Spheroidization and Grain Refinement in Steels.

\section{REFERENCES}

Chen-Chia, C. et al. (1985) Accelerated spheroidization of hypoeutectoid steel by the decomposition of supercooled austenite. Journal of Materials Science, Vol. 21, (November 1985) 3339-3344, ISSN 0022-2461

Jirkova, H. et al. (2010) Influence of Low Temperature Thermomechanical Treatment on Carbide Morphology of RSt37-2 Steel. Proceedings of the 21st International DAAAM SYMPOSIUM, Croatia, ISBN 978-3-901509-73-5, Katalinic, B. (Ed.), pp. 25-26, DAAAM International Vienna, Vienna

O'Brien, J.M. \& Hosford, W.F. (1997) Spheroidization of medium-carbon steels, JMEPEG, Vol.6, (1997) 69-72, ISSN 1059-9495

Kamyabi-Gol, A. et al (2010). Spheroidizing Kinetice and Optimization of Heat Treatment paramters in CK60 Steel Using Taguchi Robust Design. Journal of Iron and Steel Research International, Vol. 17, No. 4, (July 2010) 45-52, ISSN 1006-706X

Karadeniz, E. (2006) Influence of different intitial microstructure on the process of spheroidization in cold forging. Materials and Design, Vol. 29, (November 2006) 251-256, ISSN 0261-3069 